
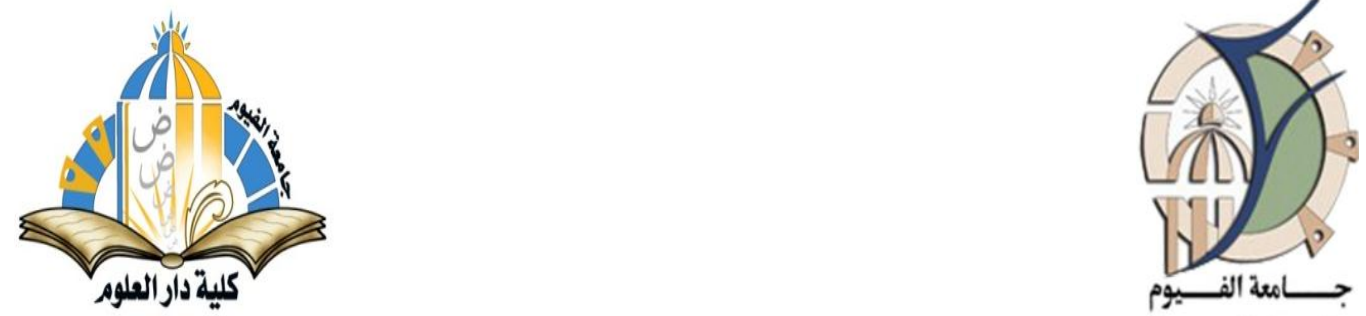

Fayoum University
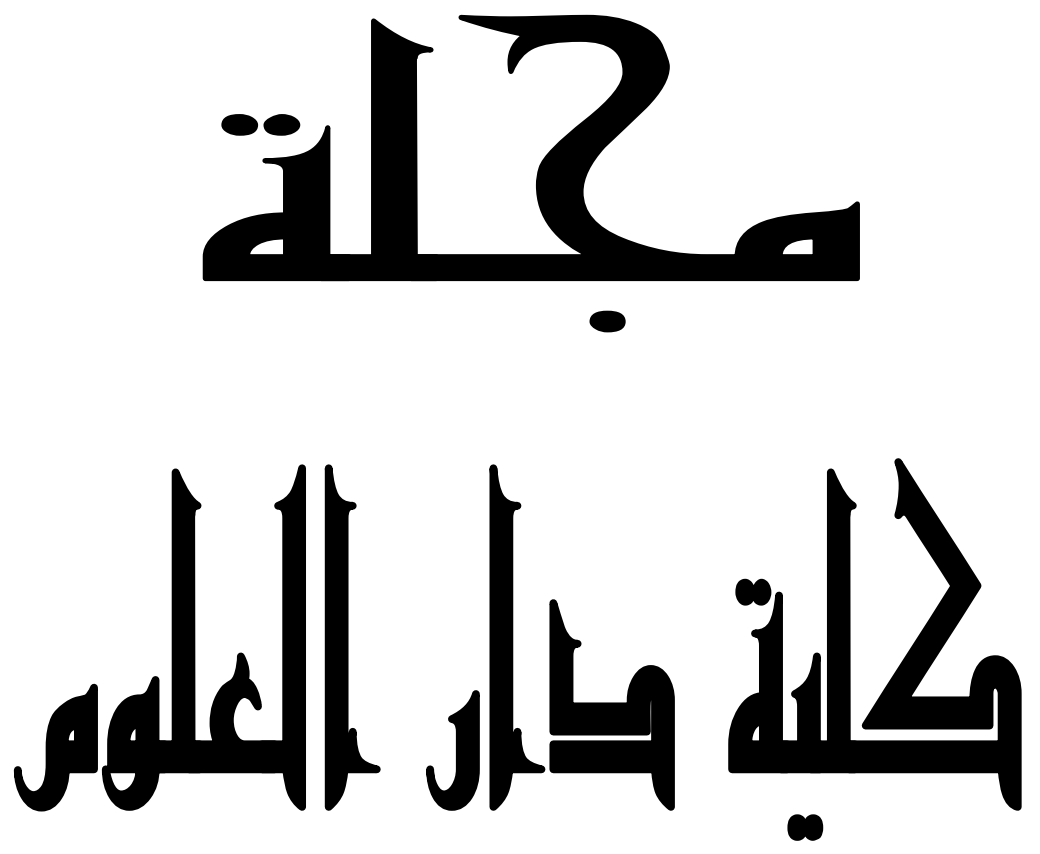

$$
\begin{aligned}
& \text { العدد V } \\
& \text { إصدار صيف ع ا • آم }
\end{aligned}
$$




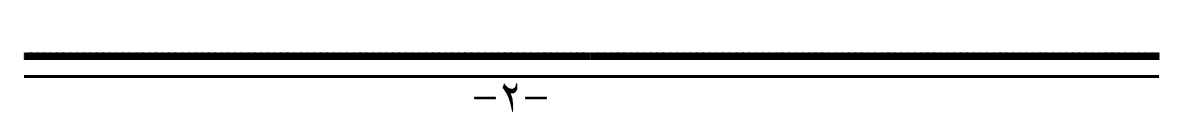




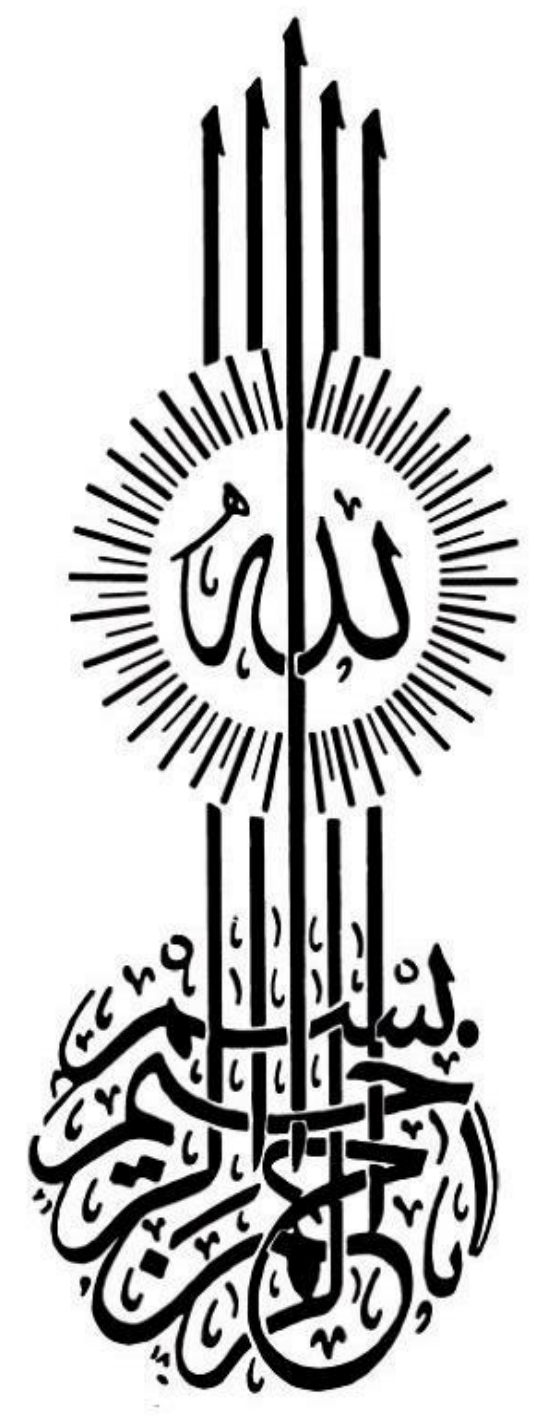




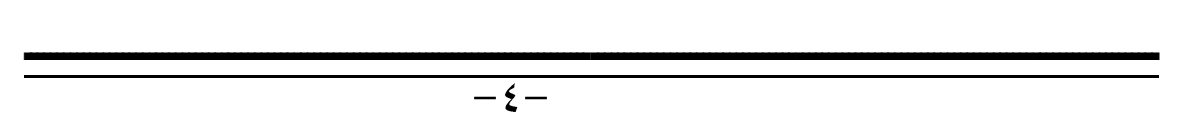




\section{تصدير العدد}

الحمد لله رب العالمين ، و الصلاة والسلام على أشرف المرسلين سيدنا

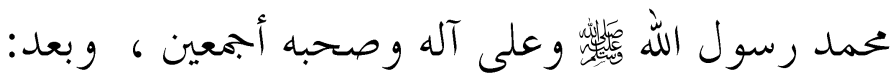

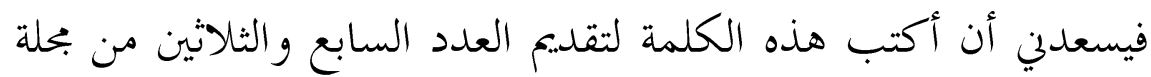

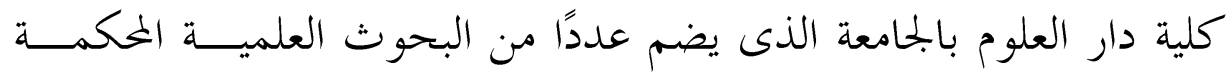

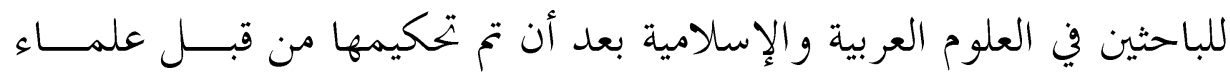

$$
\text { أجلاء من الكلية وخارجها. }
$$

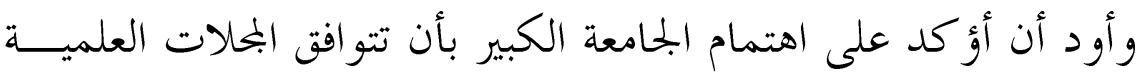

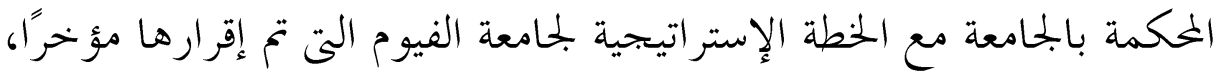
وأن يصب كل ذلك في مصلحة جامعة الفيوم تطويرا وتحديثا.

وأتوجه بالشكر إلى إدارة كلية دارالعلوم والقائمين على أمر هذه البحلة

العلمية المحكمة المرموقة على هذا الإنحاز الطيب ودعواتي دائما بالتوفيق.

الأستاذ اللكتور

خالد إسمساعيل حمزة

رئيس الجامعة 


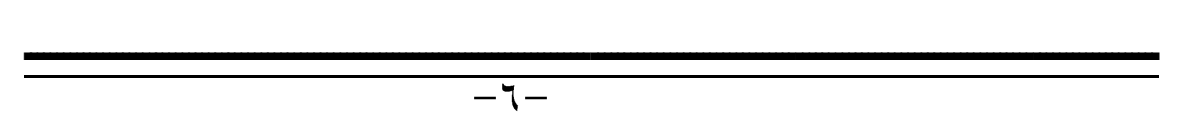




\section{مقدمة العدد}

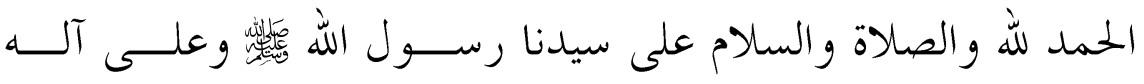

وصحبه ومن اتبع هديه والتزم بنهجه وتمسك بسنته إلى يوم الدين ، و وبعد:

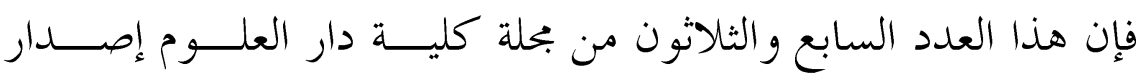

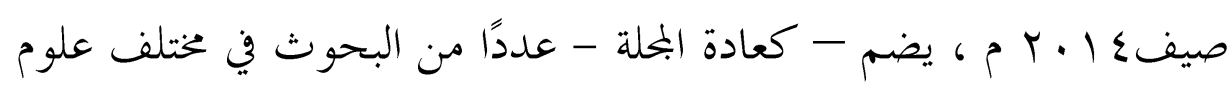
الدار وفنوها كافة ، ولقد خضعت هذه البحوث للتحكيم من قبل أساتذة

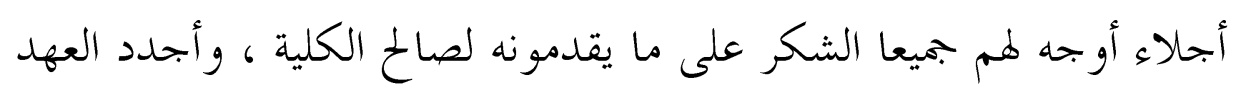

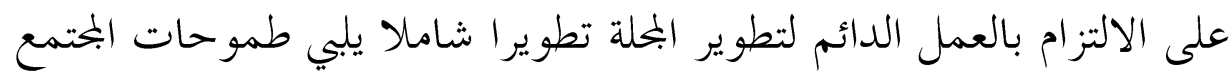

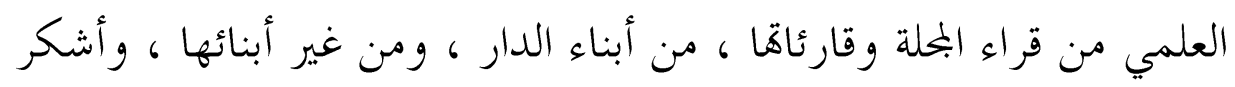

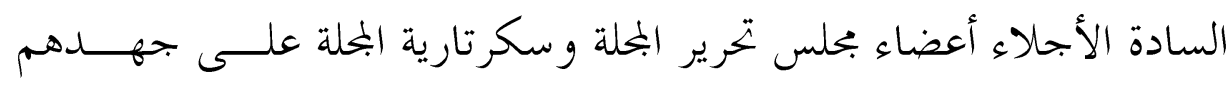
المخلص لكى يخرج هذا العدد بهذا التميز ، و الحق أن جميع أبناء دار العلوم

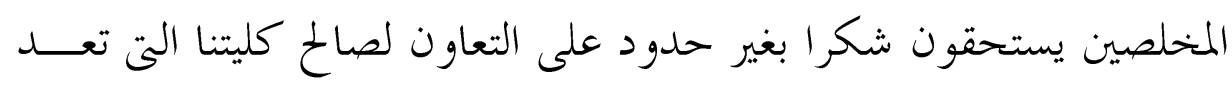

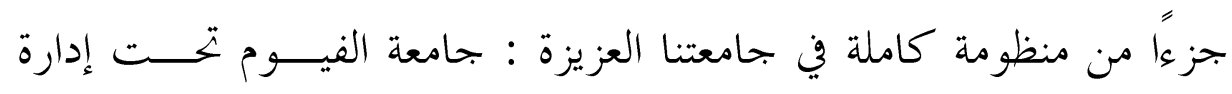

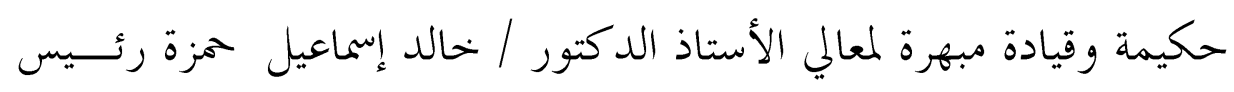

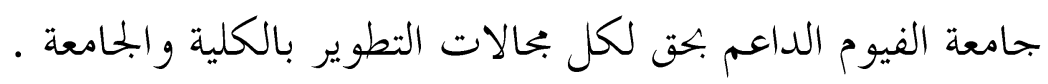

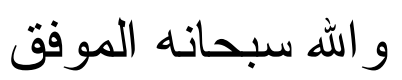

رئيس مجلس إدارة المجلة

عميد الكيس التحريز

أ.د/ صابر السبد مشالّى 
مجلس التحرير

رئيس التحرير

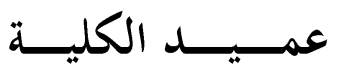

أ.د / صابر السيد مشالم

نائب رئيس التحرير

أ.د / عادل الدرغامي عبد البيي وكيل الكلية لشؤون الدراسات العليا والبحوث

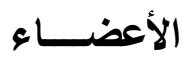

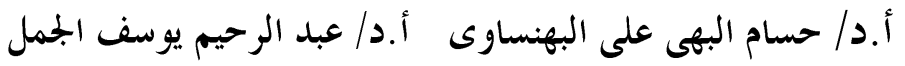
الأستاذ بقسم الدراسات الأدبية

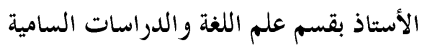

أ. أد / محمد عبد الله عفيفي

الأستاذ بقسم الفلسفة الإسلامية

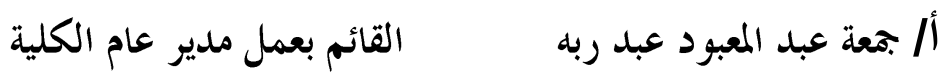

سكرتارية المجلة

أ/ هيام حسين أحدد

مدير مكتب عميد الكلية
أ/ سها سيد صوقى

رئيس قسم العلاقات الثقافية

المحكمون للعدد

أ.د. إبر اهيم محمد عبد الرحيم

أ.د. أ.د. مصطفى إبراهيم الضبع عمد عبد الرحيم

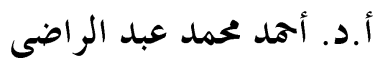

أ.د. رز رزق يوسف الثدامي

أ.د. حسام محمد نادى

أ.د. محمد حسن عبد الله

أ.د. علاء محمد رأفت حمد عبد الت
أ.د. صابر السيد مشالى

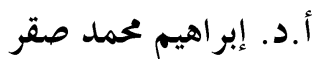

أ.د. عبد الرحيم يوسف الجمل.

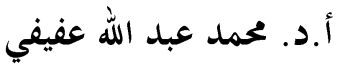

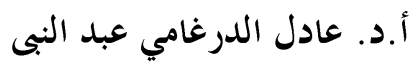

أ.أد. خليل عبد العال خليل

أ.د. محمد أبو الججد على على العال شحليل

$-\wedge-$ 


\section{قواعد النشر بالمجلة}

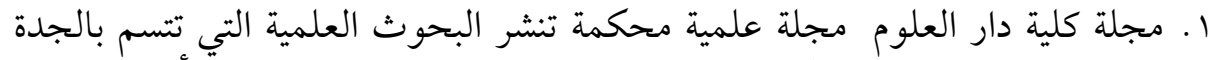

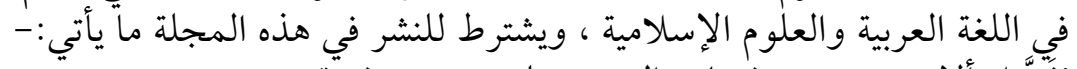

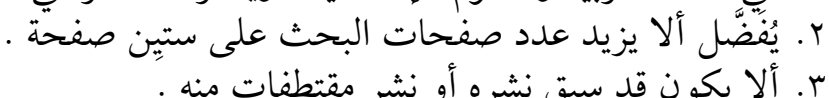

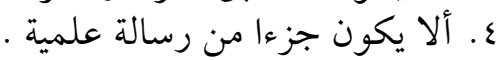

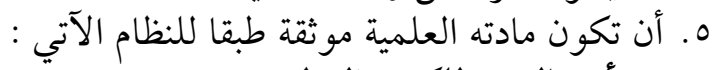

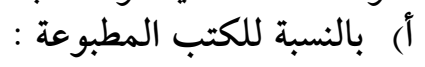
اسم المؤلف - اسم الكتاب - النبة اسم المحقق أو المترجم - الناشر - الطبعة - تاريخ

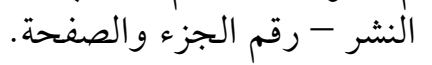

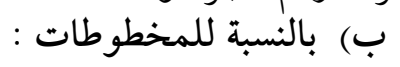
اسم المؤلف - اسم الكتاب - مكان المخطوطة - ـ رقمها - رقم اللوحة أو الصفحة .

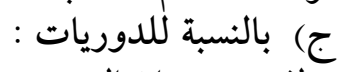

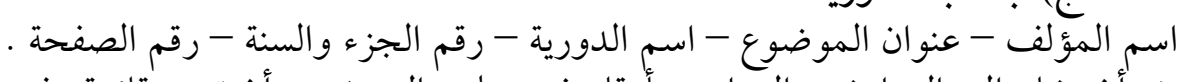

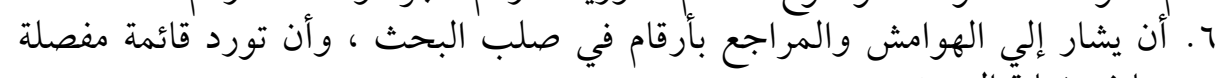

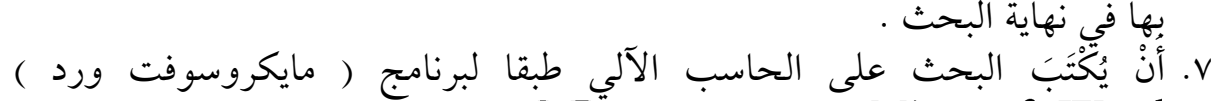
Microsoft Word

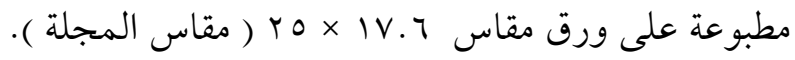

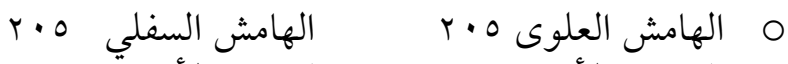

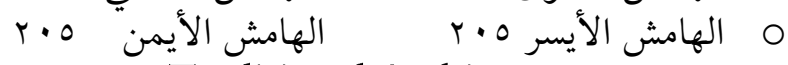

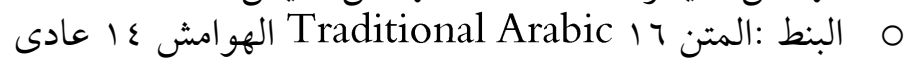

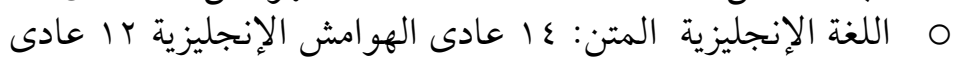

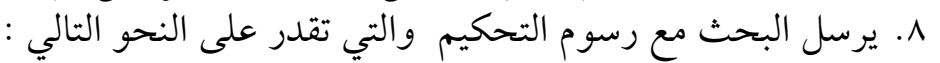

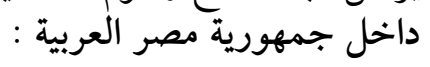

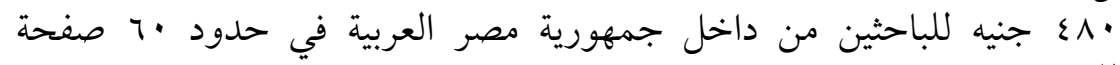

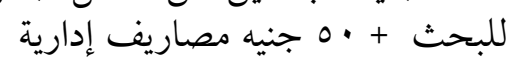

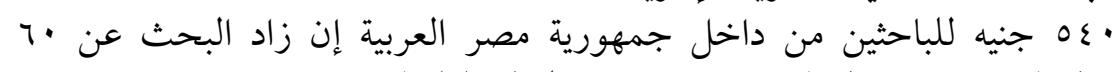

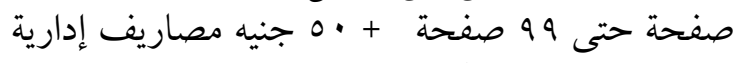
خارج جمهورية مصر العربية :

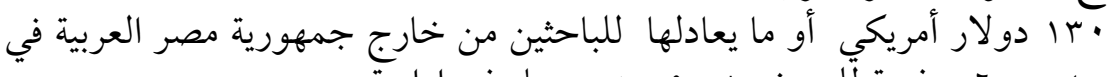

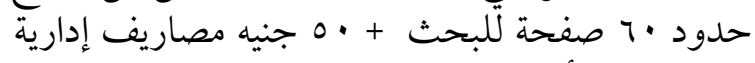

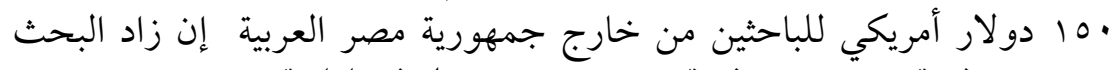

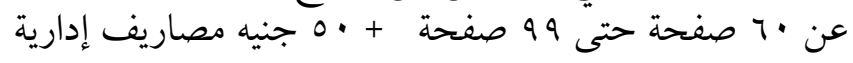

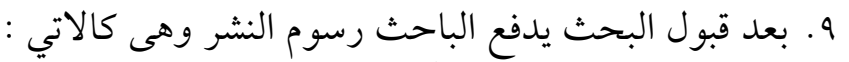
من داخل جمهورية مصر العربية : 


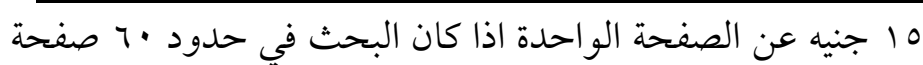

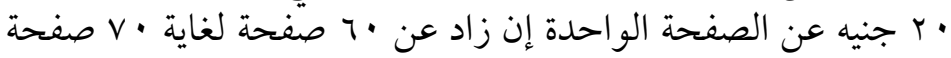

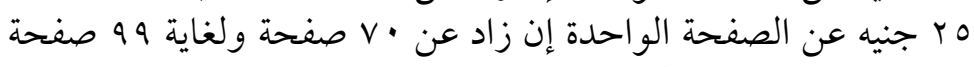

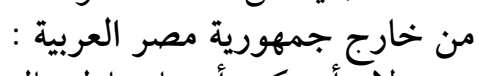
7 دولار أمريكي أو ما يعادله بالعملة مالعة المحلية عن الصفحة الواحدة اذا كان البحث

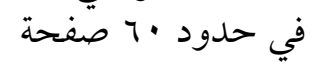

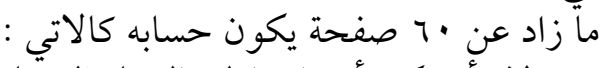

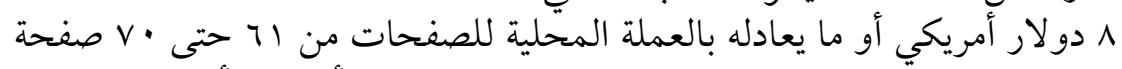

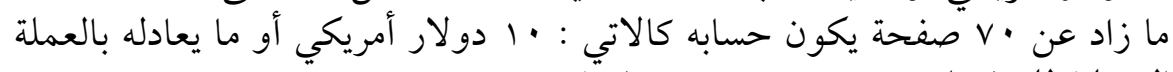

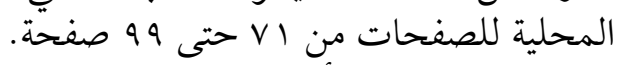

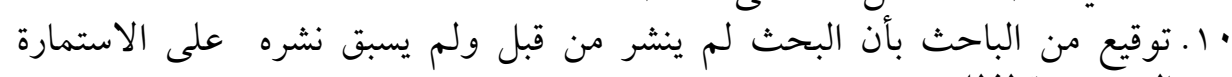

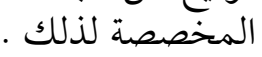
11 ـ يجوز للباحث أن يتقدم بالبحث للتحكيم فقط دون النشر بالمجلة مع الالتزام بسداد

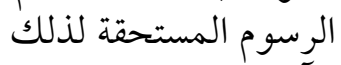
r r ا ـ الآراء الواردة في البحثة البحوث مسئولية الباحثين

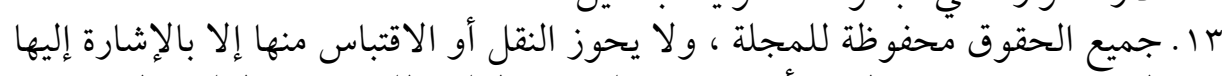

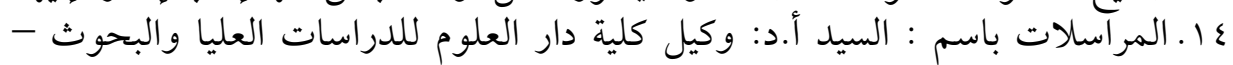

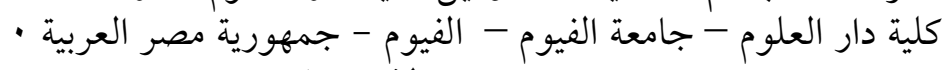
الاشتراكات : الاتمرئ

داخل جمهورية مصر العربية

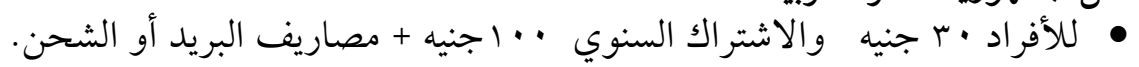

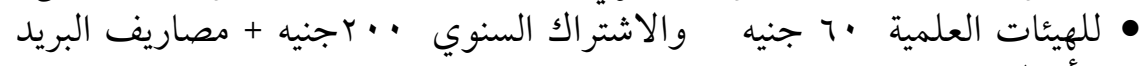

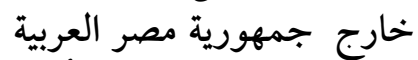
• للأفراد • إدورية دولار أمريكي أو ما يعادلها بالعملة المحلية والاشتراك السنوي

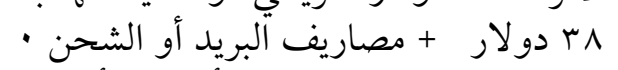

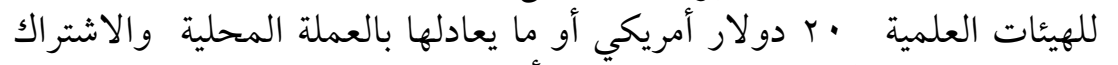

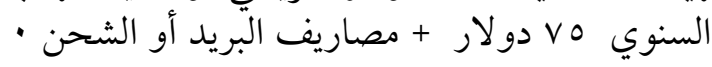
ترسل الاشتراكات مقدما باسم :

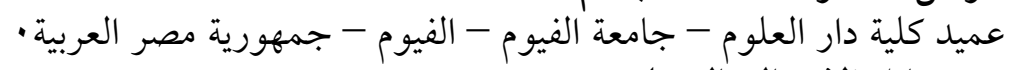
وسائل الاتصال بالمجلة

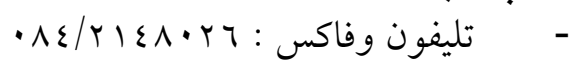
ariss@fayoum.edu.eg : البريد الإليكتروني : البريكي : dodar@fayoum.edu.eg : البريد الإليكتروني : - 